Case Report

\title{
Malignant Insulinoma with Multiple Liver Metastases and Hypercalcitoninemia in a Patient with Type 2 Diabetes Mellitus Presenting as Recurrent Episodes of Diaphoresis due to Severe Hypoglycemia
}

\author{
Marco Ciacciarelli $\mathbb{D D}^{1}$ Gianluca Caruso, ${ }^{2}$ Marco Rengo $\left(\mathbb{D},{ }^{3}\right.$ Piero Maceroni, ${ }^{3}$ \\ Carmen Misurale, ${ }^{1}$ Eleonora D'Armiento, ${ }^{1}$ Alessandro Polidoro, ${ }^{1}$ Cristina Napoli, ${ }^{1}$ \\ Alberto Lombardini, ${ }^{1}$ Umberto Ceratti, ${ }^{1}$ Ruben Manuel Luciano Colunga Biancatelli, ${ }^{1}$ \\ Leonardo Calvosa, ${ }^{1}$ Romina Milanese, ${ }^{1}$ Sonia Ferri, ${ }^{1}$ Teresa Massaro, ${ }^{1}$ Andrea Lorusso, \\ Veronica Sorrentino, ${ }^{2}$ Vincenzo Petrozza, ${ }^{2}$ and Luigi Iuliano $\mathbb{D}^{1}$ \\ ${ }^{1}$ Department of Medico-Surgical Sciences and Biotechnologies, Internal Medicine Unit, ICOT Hospital, \\ "Sapienza" University of Rome, Via Franco Faggiana 1668, Latina 04100, Italy \\ ${ }^{2}$ Department of Medico-Surgical Sciences and Biotechnologies, Pathology Unit, ICOT Hospital, "Sapienza" University of Rome, \\ Via Franco Faggiana 1668, Latina 04100, Italy \\ ${ }^{3}$ Department of Radiological Sciences, Oncology and Pathology, ICOT Hospital, "Sapienza" University of Rome, \\ Via Franco Faggiana 1668, Latina 04100, Italy
}

Correspondence should be addressed to Marco Ciacciarelli; marco.ciacciarelli@uniroma1.it

Received 11 October 2019; Revised 18 December 2019; Accepted 4 January 2020; Published 2 February 2020

Academic Editor: Mihail A. Boyanov

Copyright (C) 2020 Marco Ciacciarelli et al. This is an open access article distributed under the Creative Commons Attribution License, which permits unrestricted use, distribution, and reproduction in any medium, provided the original work is properly cited.

Insulinoma is an insulin-producing pancreatic neuroendocrine tumor that can be malignant in about $10 \%$ of cases. Locoregional invasion, lymph node metastases, or remote metastases are the main criteria of malignant insulinoma. Its incidence in patients with pre-existing diabetes mellitus (DM) is exceptionally rare. In this report, we describe a 66-year-old man with long-standing type $2 \mathrm{DM}$ who presented with recurrent episodes of diaphoresis due to severe hypoglycemia despite the withdrawal of insulin therapy, hypercalcitoninemia, and biochemical and radiological findings suggestive of metastatic malignant insulinoma. Unfortunately, after few days of diazoxide treatment, edema, hypotension, oliguria, and water retention were observed, patient's clinical status deteriorated rapidly, and he died in our department from acute renal failure.

\section{Introduction}

Insulinoma is an insulin-producing pancreatic neuroendocrine tumor (PNET) that can be malignant in about $10 \%$ of cases [1]. Locoregional invasion, lymph node metastases, or remote metastases are the main criteria of malignant insulinoma. The incidence of insulinoma, especially the malignant type, in patients with diabetes mellitus (DM) is extremely rare, and the diagnosis can be challenging due to concomitant glucose-lowering drugs, mistaken as the cause of hypoglycemia. Here, we report the case of a 66-year-old man with a medical history of long-standing type $2 \mathrm{DM}$ diagnosed with malignant metastatic insulinoma, presented as recurrent episodes of diaphoresis. Furthermore, we discuss its relevance within the contest of PNETs and similar cases described in the literature, to aware physician of this, yet rare but dramatic and challenging disease that could affect the diabetic population.

\section{Case}

A 66-year-old man was admitted to our internal medicine department for recurrent episodes of severe hypoglycemia. 
Type 2 DM was diagnosed when he was 31 years old and initially treated with oral antihyperglycemic agents. The patient discontinued oral antidiabetic agents and started insulin therapy 4 years before admission. At that time, he was treated with long-acting insulin glargine and insulin aspart. This insulin regimen was switched to insulin degludec/liraglutide 3 months before admission. While he was on insulin degludec/liraglutide, his home blood glucose monitoring ranged from 110 to $70 \mathrm{mg} / \mathrm{dL}$. Five days before admission, while on insulin degludec/liraglutide in a dose of 18 IU daily, the patient started having recurrent episodes of diaphoresis. During those episodes, usually in the early morning before breakfast, his blood glucose levels were below $50 \mathrm{mg} / \mathrm{dL}$. The patient suffered from several further episodes despite insulin dosage tapering and even after discontinuation. His past medical history was notable for heart failure with reduced ejection fraction, acute coronary syndrome, and osteomyelitis of the left foot. His family medical history included atrial fibrillation and DM. In addition to insulin, his therapy consisted in acetylsalicylic acid, bisoprolol, furosemide, ramipril, and atorvastatin. He denied oral antihyperglycemic agents. He had no known drug allergies, he was a former smoker, and he did not drink alcohol or use illicit drugs.

On admission, the patient's blood pressure was 130/ $80 \mathrm{mmHg}$, heart rate was 71 beats per minute, respiratory rate was 14 breaths per minute, and oxygen saturation was $98 \%$, while he was breathing ambient air. The patient's body mass index was $26.7 \mathrm{~kg} / \mathrm{m}^{2}$ (height: $173 \mathrm{~cm}$; weight: $80 \mathrm{~kg}$ ), and the physical examination was unremarkable. Laboratory data on admission showed glucose $50 \mathrm{mg} / \mathrm{dl}$, HbAlc $50 \mathrm{mmol} / \mathrm{mol}$, normocytic anemia (hemoglobin $11.9 \mathrm{~g} / \mathrm{dL}$, hematocrit $34.8 \%$, and mean corpuscular volume $85 \mathrm{fl}$ ), a normal white cell and platelet count, aspartate aminotransferase (AST) 87 IU/L (normal range: 17-59), alanine aminotransferase (ALT) 62 IU/1 (normal range: 21-72), gamma glutamyl-transferase 545 IU/l (normal range: 15-73), alkaline phosphatase $177 \mathrm{IU} / 1$ (normal range: 38-126), total bilirubin $0.47 \mathrm{mg} / \mathrm{dL}$ (normal range: $0.20-1.30$ ), lactate dehydrogenase $1021 \mathrm{IU} / \mathrm{L}$ (normal range: 313-618), albumin $3.5 \mathrm{~g} / \mathrm{dL}$ (normal range: 3.6-5.5), INR 1.18, C-reactive protein $7.5 \mathrm{mg} / \mathrm{dl}$ (normal range: $0-1$ ), erythrocyte sedimentation rate $90 \mathrm{~mm} / \mathrm{h}$ (normal range: 0-15), fibrinogen $621 \mathrm{mg} / \mathrm{dl}$ (normal range: 170-410), iron $37 \mu \mathrm{g} / \mathrm{dl}$ (normal range: 49-181), and ferritin $776 \mathrm{ng} / \mathrm{ml}$ (normal range: 20-325). Viral markers for hepatitis B and C were negative.

Further blood tests were ordered to rule out endogenous hyperinsulinism: C-peptide was $4.2 \mathrm{ng} / \mathrm{mL}$ (normal range: $0.5-3$ ), insulin $89 \mu \mathrm{IU} / \mathrm{mL}$ (normal range: $5-25$ ), while the patient's glucose level was $40 \mathrm{mg} / \mathrm{dL}$, and sulfonylurea screening test was negative, confirming endogenous hyperinsulinism. Markers of neuroendocrine tumors were severely increased: chromogranin A (CgA) was $1790 \mathrm{ng} / \mathrm{ml}$ (normal range: $0-100$ ), and neuron-specific enolase (NSE) was $458 \mathrm{ng} / \mathrm{ml}$ (normal range: 0-11).

Given the high suspicion of insulinoma and the altered liver function tests on admission, a full-body CT scan was ordered. CT scan showed a $4.3 \times 2.2 \mathrm{~cm}$ pancreatic tail mass containing calcifications with multiple regional lymphadenopathies (Figure 1). Multiple liver secondary lesions were found: the largest ones measuring 12 and $11 \mathrm{~cm}$, respectively, in II-III and IVb-V segments. No lungs, bone, and brain metastases were detected. Additionally, a thyroid nodule of $2.6 \mathrm{~cm}$ was incidentally found. Hepatic metastases were highly suspected to be secondary to a malignant insulinoma, so ultrasound-guided percutaneous biopsies of the lesion in the II-III segments were performed (Figure 2). Histological findings of four core biopsies consisted of hepatocytes infiltrated by a poorly differentiated and focally necrotic proliferating tissue of medium-sized atypical epithelial cells with solid growth pattern (Figure 3). The cancer cells showed hyperchromatic nuclei with "salt and pepper" chromatin markedly Ki-67 positive, high mitotic index (10 figures $\times 10$ $\mathrm{HPF}$ ), and scant cytoplasm. Immunohistochemistry studies revealed the neuroendocrine nature and the partial insulin secreting activity of the lesion; CgA, synaptophysin, CD56, and CAM5.2 were diffusely positive; there was patchy $(<5 \%)$ insulin expression. Ki-67 index was 40-50. These findings were consistent with the diagnosis of metastatic, poorly differentiated (G3), neuroendocrine carcinoma with morphology and immunophenotype favoring a pancreatic primary tumor. Thyroid ultrasound (Figure 4) showed a weakly hypoechoic solid nodule $(2.8 \times 3.2 \times 1.3 \mathrm{~cm})$ with a central cystic component and regular margins located in the isthmus and a markedly hypoechoic solid nodule $(0.9 \times 0.9 \times 0.6 \mathrm{~cm})$ adjacent to the lower pole of the left lobe. Calcifications and intranodular flow were absent in both nodules, and regional lymph nodes were not enlarged. The results of thyroid function tests were within normal limits (TSH $0.7 \mathrm{mUI} / \mathrm{L}$, normal range: 0.46-4.68), as well as were parathormone (PTH) $(80.1 \mathrm{pg} / \mathrm{mL}$, normal range: $13.6-85.8)$, calcium $(8.76 \mathrm{mg} / \mathrm{dL}$, normal range: $8.4-10.2)$, and phosphorus $(4.32 \mathrm{mg} / \mathrm{dL}$, normal range: 2.5-4.5). Serum calcitonin was slightly raised $(30 \mathrm{pg} / \mathrm{mL}$, normal range: $0-6$ ), but immunohistochemical staining of the liver lesions was negative for such markers.

The patient's hospital stay was characterized by different episodes of severe hypoglycemia (as low as $18 \mathrm{mg} / \mathrm{dL}$ ) occurring especially at night and in the early morning, manifesting only with diaphoresis. During those episodes, the patient never lost consciousness or developed seizures and even never complained of confusion, amnesia, weakness, diplopia, blurred vision, palpitations, or hunger. In order to reduce the hypoglycemic events, we started a symptomatic treatment with diazoxide and IV infusion of $10 \%$ dextrose, while waiting for histopathological confirmation of the disease. Unfortunately, due to the severity of this malignancy, after 8 days of treatment edema, hypotension, oliguria, and weight gain of $10 \mathrm{~kg}$ were observed; the patient's clinical status deteriorated rapidly, and 3 days later, the patient died from acute renal failure. Postmortem examination was not carried out according to his family's request.

\section{Discussion}

PNETs are rare neuroendocrine malignancies that count only for the $2 \%$ of total pancreatic tumors. Their incidence is around 1 case per 100,000 people, and only about $10 \%$ of 


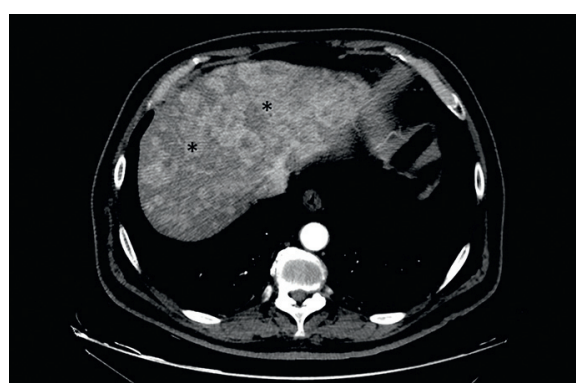

(a)

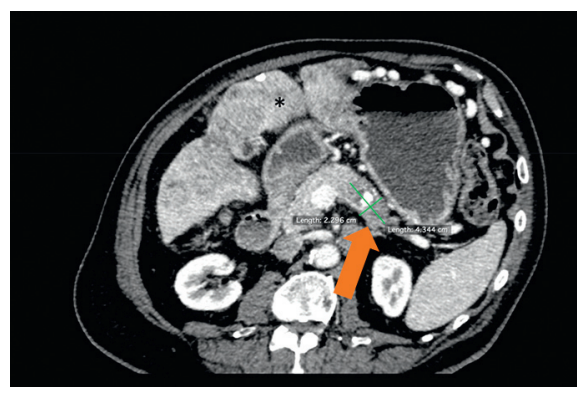

(c)

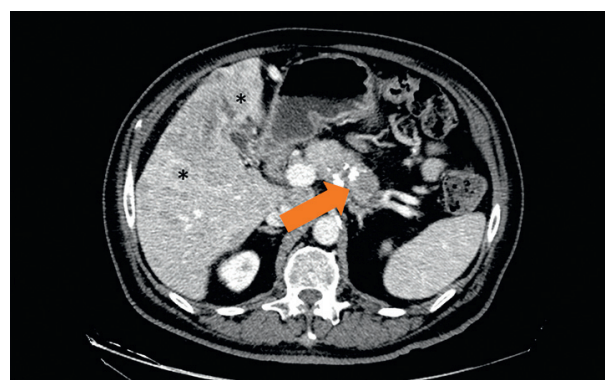

(b)

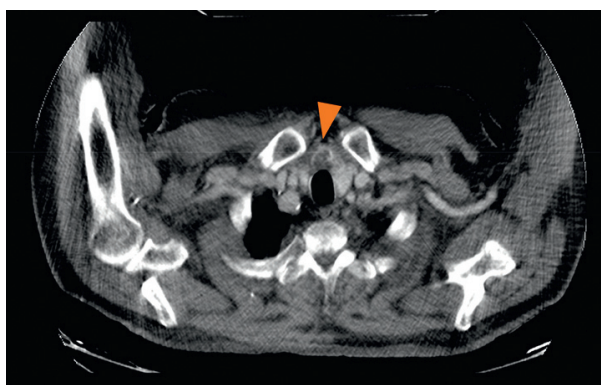

(d)

Figure 1: CT images (a)-(c) show multiple hypervascular liver metastases $(*)$ and a focal solid lesion of the pancreatic tail (arrow). A thyroid nodule (arrow head) was also detected (d).

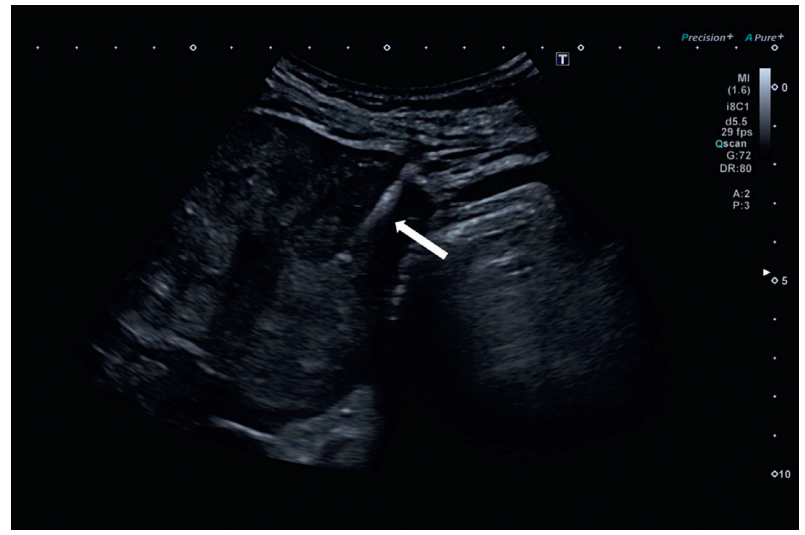

FIGURE 2: Ultrasound-guided percutaneous biopsies of the lesion located in the liver segments II-III. White arrow shows the needle penetrating in the subglissonian isoechoic/hypoechoic solid nodule with irregular margins (maximum diameter: $2.2 \mathrm{~cm}$ ).

them are classified as functional, as they release hormones or peptides that cause specific symptoms and signs [2]. With an estimated incidence of 4 cases per 1 million person-years [3], insulinomas and insulin-producing tumors, are the most common functional PNETs, and unlike other PNETs, which are malignant in $50-100 \%$ of cases, they are malignant only in about $10 \%$ of cases [4].

Locoregional invasion, lymph node metastases, or remote metastases are the main criteria of malignant insulinoma. Most patients with malignant insulinoma have lymph node or liver metastases [5-7], and only rare metastases in other sites such as bones $[8,9]$, lungs [10], brain [11], ovaries $[12,13]$, and gallbladder [14]. Liver metastases at presentation count for almost $60 \%$ of the patients with PNETs [2].
In this report, we described a malignant insulinoma with multiple liver metastases in a 66-year-old man with longstanding type $2 \mathrm{DM}$. Although benign insulinoma occurs rarely in patients with pre-existing DM [15-17], malignant insulinoma in this population seems to be even rarer, and only sparse cases are described in the literature, in both type 2 [18-23] and type $1 \mathrm{DM}[12,24,25]$. However, despite the rare occurrence of insulinoma in diabetic population, clinicians should be aware of this possible differential diagnosis when managing diabetic patients with recurrent episodes of symptomatic hypoglycemia despite tapering and withdrawal of glucose-lowering drugs. We searched the PubMed database, and to the best of our knowledge, we collected the clinical, pathologic, and biochemical data of all previously reported cases of malignant insulinoma in patients with DM (Table 1). As reported by Yu et al. [26], short hypoglycemic symptoms duration before diagnosis of tumor seems to be common in patients with malignant insulinoma (median duration: 30 days). Furthermore, as shown in the same study, high proinsulin and CgA levels and a large proinsulin/insulin molar ratio should raise the suspicion of malignant insulinoma in patients with hyperinsulinemic hypoglycemia. In our case, similarly, hypoglycemic symptoms duration before diagnosis of malignant insulinoma was short (20 days), and CgA levels were markedly elevated $(1790 \mathrm{ng} / \mathrm{ml})$. Unfortunately, we could not measure proinsulin levels and calculate proinsulin/insulin molar ratio due to laboratory limitations.

Insulinoma is a pancreatic islet cell tumor which may be associated with multiple endocrine neoplasia type 1 (MEN1). MEN-1 diagnosis was excluded because of age, a negative family medical history, and the absence of any clinical features of the most common endocrine and nonendocrine tumors associated with this rare syndrome. Primary 


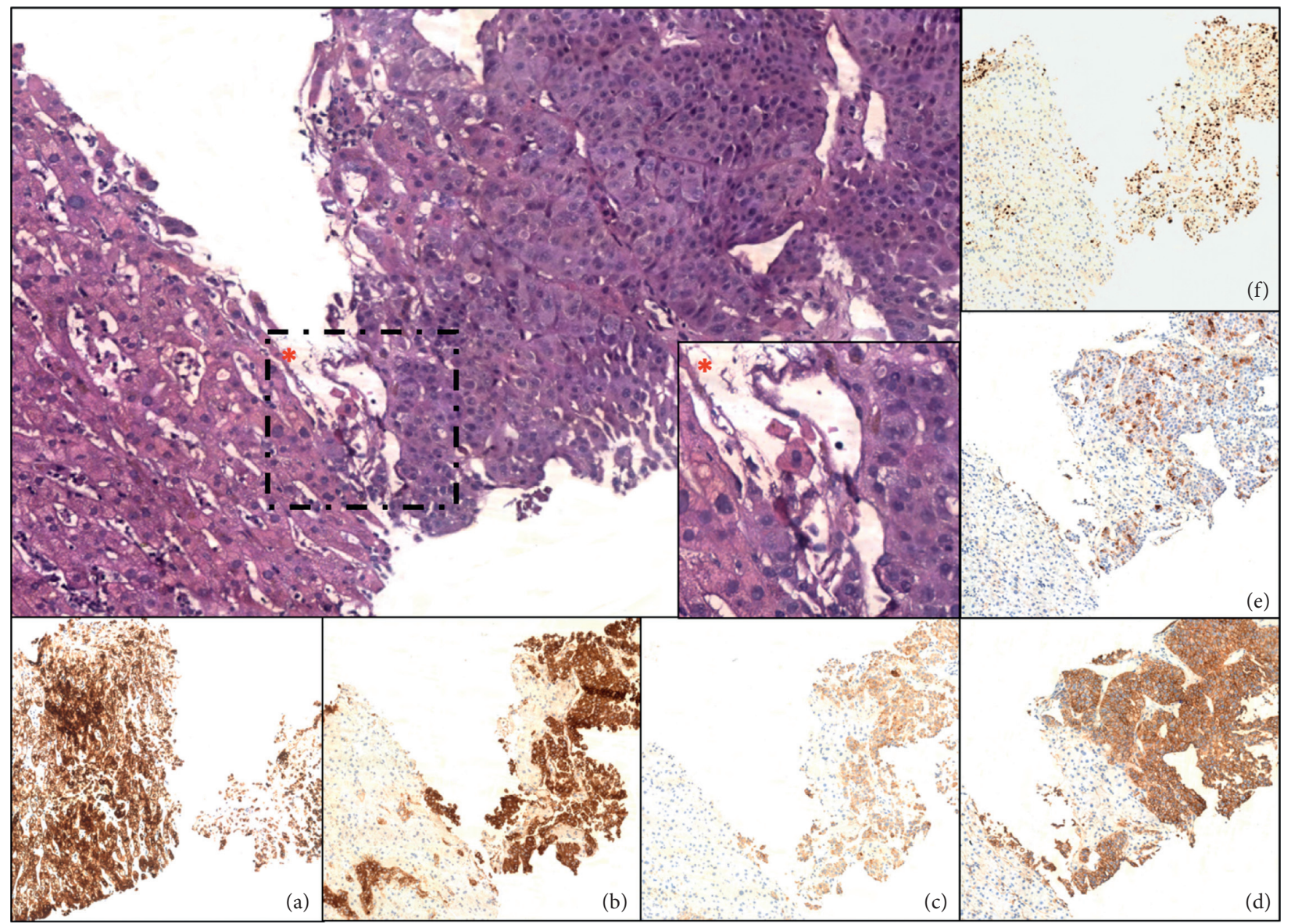

Figure 3: Poorly differentiated neuroendocrine carcinoma metastatic to the liver (H\&E, magnification: 10x). The * box represents a detailed view of neoplasia (H\&E, magnification: 40x). Immunohistochemical staining for CAM5.2 (a), synaptophysin (b), chromogranin A (c), CD56 (d), insulin (e), and Ki-67 proliferation index (f) (magnification: 10x).

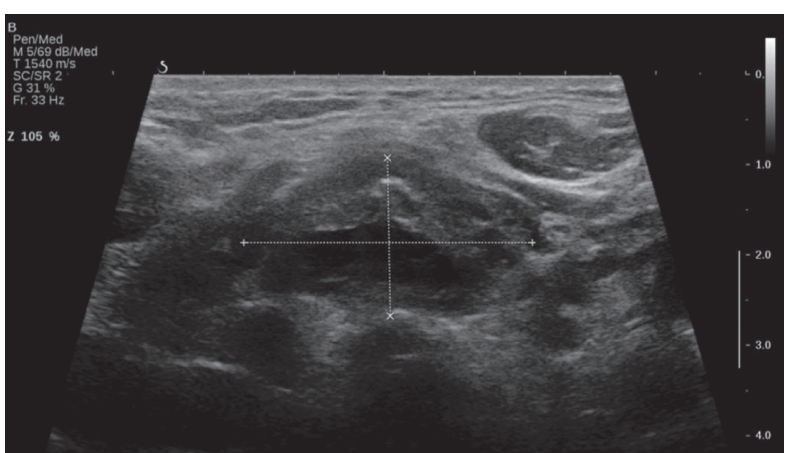

(a)

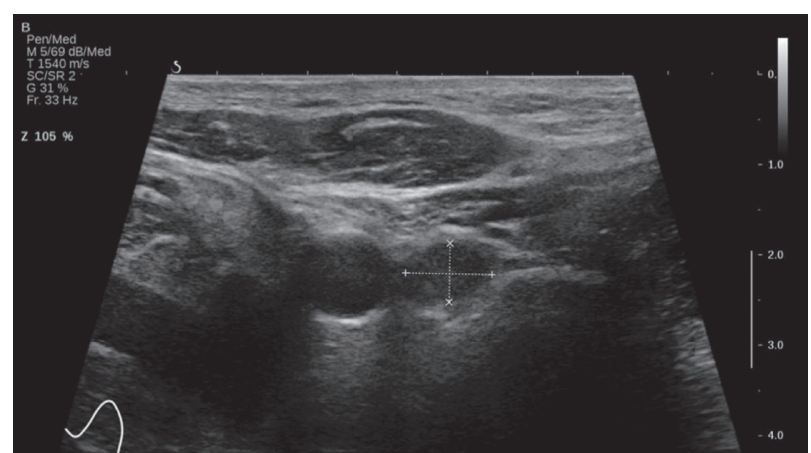

(b)

Figure 4: Thyroid ultrasound. Weakly hypoechoic solid nodule $(2.8 \times 3.2 \times 1.3 \mathrm{~cm})$ with a central cystic component and regular margins located in the isthmus (a). Markedly hypoechoic solid nodule $(0.9 \times 0.9 \times 0.6 \mathrm{~cm})$ adjacent to the lower pole of the left lobe $(\mathrm{b})$.

hyperparathyroidism is commonly associated with MEN-1, and at least $90 \%$ of patients develop it by the age of 50 years. The absence of history of osteoporosis or nephrolithiasis and normal serum calcium and PTH levels led us to rule out primary hyperparathyroidism. Since our patient had no symptoms or signs of a pituitary tumor, we did not order pituitary hormones (other than TSH) and pituitary MRI to rule out a pituitary tumor.
Metastatic insulinoma in our patient was extremely aggressive, and only progressively increased doses of diazoxide, up to $500 \mathrm{mg}$ per day, were able to avoid severe hypoglycemic episodes. Unfortunately, as reported in other cases [19], our patient rapidly developed edema, hypotension, oliguria, and water retention secondary to diazoxide toxicity and died from acute renal failure. First-line chemotherapy regimen for poorly differentiated pancreatic 


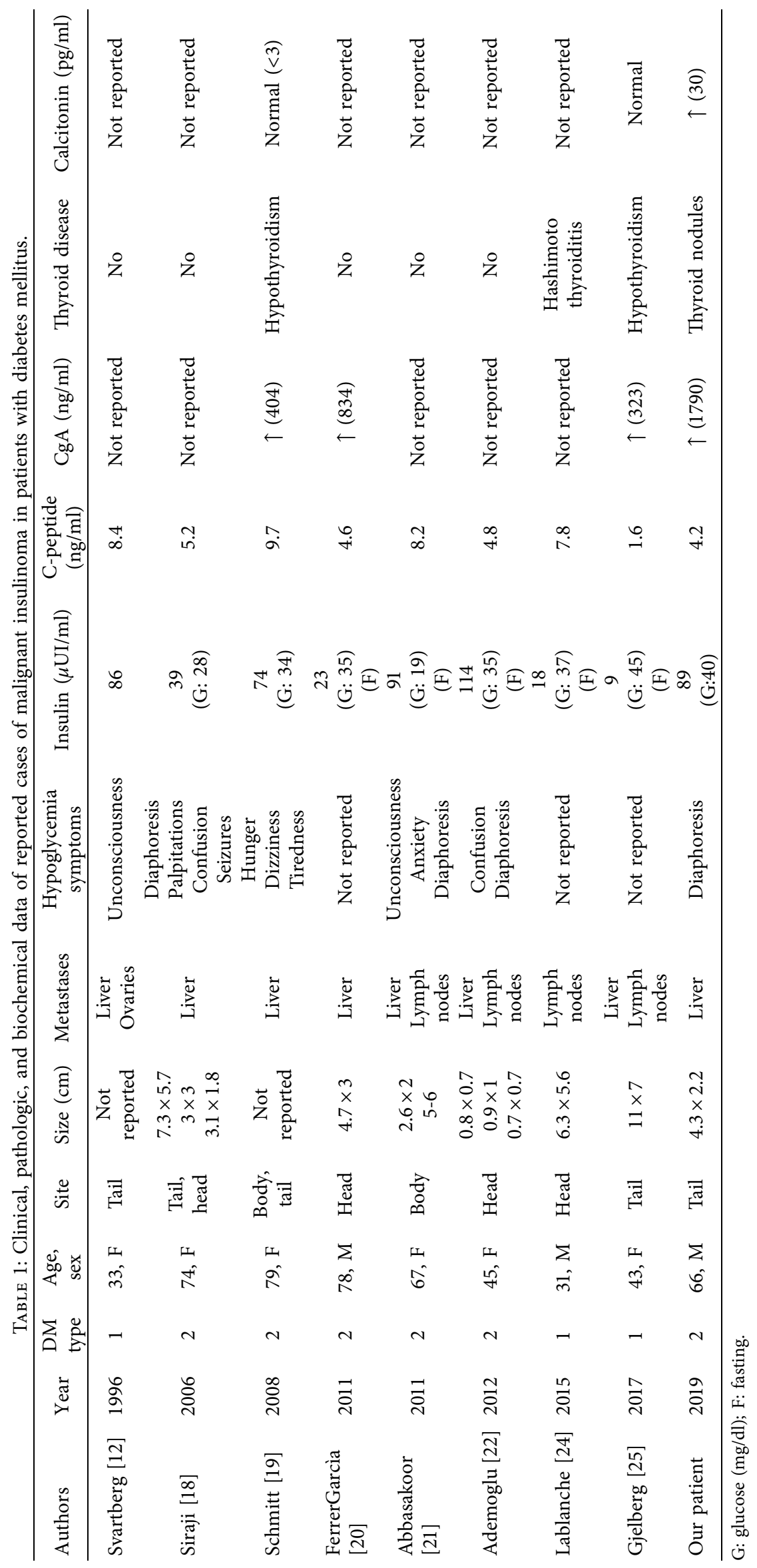


neuroendocrine carcinoma consists with a combination of etoposide and either cisplatin or carboplatin. Unfortunately, when we obtained the report of histological analysis of liver biopsy, our patient was hemodynamically unstable and his renal function has worsened significantly, so we were not able to start chemotherapy with traditional regimen. Everolimus is an mTOR inhibitor with hyperglycemic and antitumoral effects indicated in treatment of malignant insulinoma. Given its toxicity, it is used as third-line treatment of recurrent episodes of hypoglycemia after failure of diazoxide and somatostatin analogs. The antitumoral effect of everolimus has been shown to improve progressionfree survival of patients with well-differentiated PNETs. However, the antitumor efficacy of everolimus in poorly differentiated pancreatic neuroendocrine carcinoma remains to be determined.

Interestingly, our patient displayed increased serum calcitonin levels (30 pg/ml, normal range 0-6). Calcitonin is a peptide hormone secreted by $\mathrm{C}$ cells of the thyroid that acts as a physiologic antagonist to PTH, lowering blood calcium levels. Despite hypercalcitoninemia is a typical marker of medullary thyroid carcinoma (MTC), calcitonin can be found increased in several conditions: after exhausting physical activity, because of interfering drugs, in thyroid and non-thyroid diseases. These conditions should be always ruled out in cases with basal calcitonin values between 10 and $100 \mathrm{pg} / \mathrm{mL}$ [27], as observed in our patient.

He was sedentary, and at the time of blood sample analysis, he was not taking interfering drugs (e.g., omeprazole, glucocorticoids, or beta-blockers). In fact, bisoprolol was discontinued on admission in the attempt of increasing the adrenergic warning symptoms of hypoglycemia. Although glucagon-like peptide 1 analogs such as liraglutide are well known to cause slightly increases of calcitonin, we rejected this hypothesis because our patient discontinued liraglutide 22 days before calcitonin measurement.

Follicular and papillary thyroid carcinomas are thyroid diseases that may be associated to slightly raised calcitonin levels. Although the two thyroid nodules of our patient appeared benign and did not show any signs of malignancy (e.g., calcifications, intranodular flow, taller-than-wide shape, irregular margins, local invasion of surrounding structures, suspicious neck lymph nodes), we could not completely rule out any type of thyroid carcinoma, including MTC, as fine needle aspiration was not carried out due to severe worsening of the patient's clinical status. However, it is unlikely that ultrasound thyroid findings paired with thyroid malignancies and two different neuroendocrine tumors such as MTC and malignant insulinoma developed simultaneously.

Hypercalcitoninemia may also occur in nonthyroid diseases such as chronic renal failure, hyperparathyroidismrelated hypercalcemia, and hypergastrinemia. Our patient had normal renal function, normal calcium levels, and no clinical features of conditions commonly associated with hypergastrinemia such as atrophic gastritis and gastrinoma; therefore, serum gastrin levels were not measured.

Hypercalcitoninemia due to ectopic calcitonin secretion by several types of PNETs, including insulinoma, has been described [28-33]; therefore, we measured calcitonin levels even if our patient had no family history of MTC or clinical and laboratory findings consistent with hyperparathyroidism or pheochromocytoma. Moreover, hypercalcitoninemia due to calcitonin-producing insulinoma has been documented in patients with benign thyroid nodules [31, 32].

Since a specific endocrine syndrome related to hypercalcitoninemia has not been identified yet, calcitonin-producing PNETs are currently classified as nonfunctional, unless they secrete "eutopic" biologically active hormones (insulin, glucagon, somatostatin, and pancreatic polypeptide). Interestingly, according to Uccella et al. [33], calcitonin expression is not related to either a more aggressive behavior or a worse prognosis, so it seems to not identify a separate subset of PNETs. The immunohistochemical detection of calcitonin in cells from pancreatic mass and the normalization of its value after tumor resection are important findings in confirming the diagnosis of calcitoninproducing insulinoma $[29,31,32]$. Due to the history of heart failure with reduced ejection fraction and the high suspicion of liver metastases, we performed a less-invasive diagnostic procedure such as liver biopsy rather than endoscopic ultrasound-guided biopsies of the pancreatic mass, as successfully reported in similar cases [5-7]. To the best of our knowledge, the few cases of calcitonin-producing insulinoma reported in the literature were not associated to metastases in liver or in other sites. In our case, immunohistochemistry of the liver lesion was negative for calcitonin; however, it should be noted that immunostaining of hepatic lesions secondary to calcitonin-producing PNETs may be negative for calcitonin probably because metastases can dedifferentiate and lose their secretory activity [34].

Despite the diagnosis of malignant insulinoma in our patient was made with biopsy of liver metastasis rather than biopsy of the pancreatic mass, in the absence of other apparent causes of hypercalcitoninemia, we hypothesized that cells of the pancreatic malignancy were able to produce calcitonin with following elevation of this serum marker.

\section{Conclusion}

In conclusion, although very rare, malignant insulinoma can occur in patients with both type 2 and type $1 \mathrm{DM}$. Most patients with malignant insulinoma have lymph node or liver metastases at presentation. Malignant insulinoma with liver metastases should always be considered as a cause of recurrent episodes of symptomatic hypoglycemia in diabetic patients with altered liver function tests, especially when severe hypoglycemia persists after withdrawal of glucoselowering agents.

Furthermore, this case underlines that hypercalcitoninemia in patients with thyroid nodules is not necessarily due to MTC. Several physiologic and pathologic conditions other than MTC have been associated with increased calcitonin levels, including calcitonin-producing PNETs. Since the majority of PNETs are malignant, nonfunctional and hence represent a diagnostic challenge for physicians, all patients with raised calcitonin levels and thyroid nodules not clearly suggestive of MTC should be 
submitted to a careful investigation in order to rule out a calcitonin-producing PNET, a rare but recognized cause of hypercalcitoninemia.

\section{Conflicts of Interest}

The authors declare no conflicts of interest regarding the publication of this paper.

\section{References}

[1] B. Hirshberg, C. Cochran, M. C. Skarulis et al., "Malignant insulinoma," Cancer, vol. 104, no. 2, pp. 264-272, 2005.

[2] A. Lewis, D. Li, J. Williams, and G. Singh, "Pancreatic neuroendocrine tumors: state-of-the-art diagnosis and management," Oncology (Williston Park, NY), vol. 31, no. 10, pp. e1-12, 2017.

[3] F. J. Service, M. M. McMahon, P. C. O'brien, and D. J. Ballard, "Functioning insulinoma-incidence, recurrence, and longterm survival of patients: a 60-year study," Mayo Clinic Proceedings, vol. 66, no. 7, pp. 711-719, 1991.

[4] D. W. Lee, M. K. Kim, and H. G. Kim, "Diagnosis of pancreatic neuroendocrine tumors," Clinical Endoscopy, vol. 50, no. 6 , pp. 537-545, 2017.

[5] C. Toyoda, K. Hosokawa, Y. Atsumi et al., "Malignant insulinoma with extensive liver metastases presenting as disturbance of consciousness," Internal Medicine, vol. 37, no. 5, pp. 476-479, 1998.

[6] R. Baldelli, G. Ettorre, G. Vennarecci et al., "Malignant insulinoma presenting as metastatic liver tumor. Case report and review of the literature," Journal of Experimental \&amp; Clinical Cancer Research: CR, vol. 26, no. 4, pp. 603-607, 2007.

[7] A. Barnabei, E. Askin, F. Kose et al., "Erratum to: rapidly progressing malignant insulinoma presented with multiple liver metastases: a case report," Journal of Gastrointestinal Cancer, vol. 41, no. 4, pp. 272-274, 2010.

[8] C. S. Hesdorffer, M. Stoopler, and J. Javitch, "Aggressive insulinoma with bone metastases," American Journal of Clinical Oncology, vol. 12, no. 6, pp. 498-501, 1989.

[9] A. Naganuma, H. Mayahara, C. Morizane et al., "Successful control of intractable hypoglycemia using radiopharmaceutical therapy with strontium-89 in a case with malignant insulinoma and bone metastases," Japanese Journal of Clinical Oncology, vol. 42, no. 7, pp. 640-645, 2012.

[10] A. Albu, A. Zirnea, O. Georgescu, D. Terzea, D. Jinga, and S. Fica, "Malignant insulinoma with hepatic and pulmonary metastases associated with primary hyperparathyroidism. Case report and review of the literature," Journal of Medicine and Life, vol. 1, no. 2, pp. 210-217, 2008.

[11] J. L. Frazier and J. D. Weingart, "Metastatic insulinoma to the brain," Endocrinologist, vol. 19, no. 1, p. 5, 2009.

[12] J. Svartberg, M. Stridsberg, E. Wilander, D. E. H. Andersson, and B. Eriksson, "Tumour-induced hypoglycaemia in a patient with insulin-dependent diabetes mellitus," Journal of Internal Medicine, vol. 239, no. 2, pp. 181-185, 1996.

[13] O. Bélissant Benesty, T. Cassou-Mounat, C. Vatier, J.-N. Talbot, and F. Montravers, "Tumor heterogeneity detected by $68 \mathrm{Ga}$ DOTATOC and $18 \mathrm{~F}-\mathrm{FDG}$ PET/CTs in one malignant insulinoma with involvement of the portal splenic confluence and ovarian metastases," Clinical Nuclear Medicine, vol. 41, no. 11, pp. 874-876, 2016.

[14] M. Imamura, E. Miyashita, K. Miyagawa, S. Matsuno, and T. Sato, "Malignant insulinoma with metastasis to gallbladder and bone, accompanied by past history of peptic ulcer and hyperthyroidism," Digestive Diseases and Sciences, vol. 32, no. 11, pp. 1319-1324, 1987.

[15] L. A. Kane, C. S. Grant, T. B. Nippoldt, and F. J. Service, "Insulinoma in a patient with NIDDM," Diabetes Care, vol. 16, no. 9, pp. 1298-1300, 1993.

[16] H. Ishii, T. Ito, S. Moriya, Y. Horie, and M. Tsuchiya, "Insulinoma-a statistical review of 443 cases in Japan," Nippon Rinsho, vol. 51, no. Suppl, pp. 199-206, 1993.

[17] W.-Y. Lei, T.-E. Wang, T.-L. Chen, W.-H. Chang, T.-L. Yang, and C.-Y. Wang, "Insulinoma causing hypoglycemia in a patient with type 2 diabetes," Journal of the Formosan Medical Association, vol. 106, no. 5, pp. 392-396, 2007.

[18] E. S. Siraj, G. Samuel, S. Saber, S. Samuel, A. H. Hamrahian, and S. S. K. Reddy, "Metastatic malignant insulinoma in a patient with type 2 diabetes mellitus: case presentation and literature review," Endocrine Practice, vol. 12, no. 4, pp. 411-416, 2006.

[19] J. Schmitt, S. Boullu-Sanchis, F. Moreau et al., "Association of malignant insulinoma and type 2 diabetes mellitus: a case report," Annales d'Endocrinologie, vol. 69, no. 1, pp. 69-72, 2008.

[20] J. Ferrer-García, M. Tolosa-Torréns, C. Hernando-Meliá, L. Arribas-Palomar, and C. Sánchez-Juan, "Everolimus resolving hypoglycemia, producing hyperglycemia, and necessitating insulin use in a patient with diabetes and nonresectable malignant insulinoma," Endocrine Practice, vol. 17, no. 2, pp. e17-e20, 2011.

[21] N. O. Abbasakoor, M. L. Healy, D. O’Shea et al., "Metastatic insulinoma in a patient with type 2 diabetes mellitus: case report and review of the literature," International Journal of Endocrinology, vol. 2011, Article ID 124078, 5 pages, 2011.

[22] E. Ademoğlu, U. Unlütürk, K. Ağbaht, A. Karabork, and D. Corapçioğlu, "Type 2 diabetes mellitus in a patient with malignant insulinoma manifesting following surgery," Diabetic Medicine, vol. 29, no. 7, pp. e133-137, 2012.

[23] V. I. Podzolkov, N. A. Dragomiretskaia, T. V. Koroleva, N. N. Kavtaradze, H. H. Iakovleva, and A. V. Podzolkov, "A rare case of hypoglycemia in an elderly patient with type 2 diabetes mellitus: malignant metastasizing insulinoma," Klin Med (Mosk).vol. 92, no. 2, pp. 65-70, 2014.

[24] S. Lablanche, M. Chobert-Bakouline, O. Risse, M.-H. Laverrière, O. Chabre, and P.-Y. Benhamou, "Malignant insulinoma may arise during the course of type 1 diabetes mellitus: a case report," Diabetes \& Metabolism, vol. 41, no. 3, pp. 258-261, 2015.

[25] H. K. Gjelberg, D. Hoem, C. S. Verbeke, J. Eide, J. G. Cooper, and A. Molven, "Hypoglycemia and decreased insulin requirement caused by malignant insulinoma in a type 1 diabetic patient: when the hoof beats are from a zebra, not a horse," Clinical Case Reports, vol. 5, no. 6, pp. 761-768, 2017.

[26] R. Yu, N. N. Nissen, A. Hendifar et al., "A clinicopathological study of malignant insulinoma in a contemporary series," Pancreas, vol. 46, no. 1, pp. 48-56, 2017.

[27] S. P. Fan, D. M. Lourenço, M. A. Santos, M. R. Tavares, R. A. Toledo, and J. E. de Menezes Correia-Deur, "Hypercalcitoninemia is not pathognomonic of medullary thyroid carcinoma," Clinics (Sao Paulo).vol. 64, no. 7, pp. 699-706, 2009.

[28] A. Ooi, I. Nakanishi, T. Kameya, Y. Funaki, and K. Kobayashi, "Calcitonin-producing insulinoma: an immunohistochemical and electron microscopic study," Pathology International, vol. 36, no. 12, pp. 1897-1903, 1986.

[29] D. E. Price, S. R. Absalom, K. Davidson, A. Bolia, P. R. F. Bell, and T. A. Howlett, "A case of multiple endocrine neoplasia: 
hyperparathyroidism, insulinoma, GRF-OMA, hypercalcitoninaemia and intractable peptic ulceration," Clinical Endocrinology, vol. 37, no. 2, pp. 187-188, 1992.

[30] A. Gaulier, J. Cahen, J. L. Buisson, G. Périé, G. Vacher, and B. Poulet, "Pancreatic insulinoma, adenomatosis of the Wirsung's duct and chronic pancreatitis. Apropos of a case," Archives d'anatomie et de cytologie pathologiques, vol. 41, no. 5-6, pp. 245-250, 1993.

[31] M. J. G. M. Bugalho, L. Roque, L. G. Sobrinho et al., "Calcitonin-producing insulinoma: clinical, immunocytochemical and cytogenetical study," Clinical Endocrinology, vol. 41, no. 2, pp. 257-260, 1994.

[32] P. Pusztai, B. Sármán, G. Illyés et al., "Hypercalcitoninemia in a patient with a recurrent goitre and insulinoma: a case report," Experimental and Clinical Endocrinology \& Diabetes, vol. 114, no. 05, pp. 217-221, 2006.

[33] S. Uccella, A. Blank, R. Maragliano, F. Sessa, A. Perren, and S. La Rosa, "Calcitonin-producing neuroendocrine neoplasms of the pancreas: clinicopathological study of 25 cases and review of the literature," Endocrine Pathology, vol. 28, no. 4, pp. 351-361, 2017.

[34] E. Giannetta, D. Gianfrilli, C. Pozza et al., "Extrathyroidal calcitonin secreting tumors," Medicine, vol. 95, no. 3, p. e2419, 2016. 